\title{
Paleomagnetism and electron microscopy of the Emeishan Basalts, Yunnan, China
}

\author{
Rob Van der Voo ${ }^{a}$, Wu Fang ${ }^{a}$, Zhongmin Wang ${ }^{\text {a }}$, Dongwoo Suk ${ }^{\text {a }}$, Donald R. Peacor ${ }^{\text {a }}$ \\ and Qizhong Liang ${ }^{b}$ \\ a Department of Geological Sciences, University of Michigan, 1006 C.C. Little Building, Ann Arbor, MI 48109-1063, USA \\ ${ }^{b}$ Yunnan Institute of Geological Sciences, Kunming, Yunnan, People's Republic of China
}

(Received June 22, 1992; revised version accepted November 9, 1992)

\begin{abstract}
Many normal and a few reversed characteristic directions of magnetization have been obtained by predominantly thermal demagnetization from ten sites of the Late Permian Emeishan Basalts collected near Kunming, Yunnan Province. The normal magnetization directions pass a fold test at the $99 \%$ confidence level and yield declination $/$ inclination $=26 \%$ $12^{\circ}, k=46, \alpha_{95}=6^{\circ}$ and a paleopole at $50^{\circ} \mathrm{N}, 241^{\circ} \mathrm{E}$. However, the reversed-polarity directions, with declination/inclination at $244^{\circ} /+3^{\circ}$ are not antipodal to the normal ones, which is also noted in other studies of the Emeishan Basalts of the Yangtze Paraplatform of the South China Block. Speculations about the cause of this lack of antipodality center on: (1) local relative rotations, (2) incomplete demagnetization, (3) unusually large non-dipole fields, secular variation or asymmetric reversals in the Late Permian, (4) errors in sample orientation, or (5) later remagnetization represented by one or the other polarity group. The first two causes are ruled out by our observations, and the third cannot be tested with data from China alone but is unlikely because it has not been observed elsewhere. Errors in sample orientation may be present in those studies that used a magnetic compass, because sample intensities of magnetization are on the high side. However, for the normal-polarity directions, a solar compass has been used in some of the studies and all normal-polarity directions observed in the area are in agreement. Thus, sample orientation errors can be invoked only for the reversed-polarity directions. In order to test cause (5), we have examined the magnetic carriers in eight samples with scanning electron microscopy. Titanium-poor to titanium-rich magnetite, commonly cruciform in crystal habit, indicates primary igneous crystallization in two samples that have NE and WSW declinations. In contrast, six normal-polarity samples with NNE declinations show pervasive replacement of original titanomagnetite by titanium-free magnetite and sphene, indicating a high degree of alteration. We ascribe this alteration to late hydrothermal circulation and argue that it has caused remagnetization in post-Permian times. This study suggests, therefore, that the NE-SW directions are more likely to be representative of the Late Permian paleomagnetic field than the NNE directions.
\end{abstract}

\section{Introduction}

Several previously published studies have obtained coherent characteristic magnetizations from the Late Permian Emeishan Basalts in southwest China (Table 1) in Sichuan, Guizhou and northern Yunnan provinces. Figure $1(a, b)$ illustrates the sampling localities and the normal and reversed directions observed. It is clear that these directions are not antipodal and this has led to uncertainties about the validity of the Emeishan paleopoles. A comparison between Late Permian paleopoles from north and south
China (e.g., Zhao and Coe, 1987) shows a large (ca. $70^{\circ}$ ) relative rotation of these two blocks. Similar Triassic declination differences suggest that the rotation occurred during the Jurassic at which time the two blocks were sutured together in the Qinling mobile belt. The details of the Permo-Triassic positions of the South China Block are obscure, however, because of the above-mentioned uncertainties regarding the Emeishan poles.

In the Emei stratotype section south of the city of Chengdu where most of the sampling was carried out (Fig. 1a), only a northerly and shallow 
upward direction is observed. Because the basalt eruption was thought to have occurred during the late Paleozoic Kiaman reversed interval, the first studies led McElhinny et al. (1981) to interpret this northerly direction as one of reversed polarity, with significant implications for the inferred movements of the South China Block. The subsequent discovery of reversals and improvements in our knowledge about the Late Permian (post-Kiaman) age of the rocks caused a reinterpretation (McElhinny, 1985; Huang et al., 1986; Zhao and Coe, 1987) and there is now general consensus about the choice of polarity. However, differ- ences in declination between the normal and reversed mean directions, which generally came from different localities, subsequently led to doubt about local rotations, especially for sites near the Longmenshan Thrust Fault that forms the westcrn boundary of the South China Block; tilt corrections of steeply dipping strata also may have introduced aberrant declinations because of possibly plunging fold axes (e.g., MacDonald, 1980). Alternatively, partial to complete remagnetizations have been inferred as the explanation for the normal polarity directions (Lin et al., 1985; Lin, 1989), given that they yield a paleopole that

\section{TABLE 1}

Paleomagnetic results from the Emeishan Basalts and other Permo-Triassic rocks

\begin{tabular}{|c|c|c|c|c|c|c|c|c|}
\hline Nr. & Locality & Coordinates & Decl/Incl & $N / n$ & $A_{95}$ & Paleopole & $P$ & Reference \\
\hline \multicolumn{9}{|c|}{$\overline{\text { Basalts }}$} \\
\hline 1 & Emei & $29.6^{\circ} \mathrm{N}, 103.4^{\circ} \mathrm{E}$ & $18.4^{\circ} /-6.5^{\circ}$ & $22 / 142$ & $6.2^{\circ}$ & $53.7^{\circ} \mathrm{N}, 252.1^{\circ} \mathrm{E}$ & $\mathrm{N}$ & $\begin{array}{l}\text { McElhinny et al. } \\
\text { (1981) }\end{array}$ \\
\hline 2 & Emei & $29.6^{\circ} \mathrm{N}, 103.4^{\circ} \mathrm{E}$ & $21.4^{\circ} /-7.6^{\circ}$ & $20 / 72$ & $3.3^{\circ}$ & $50.7^{\circ} \mathrm{N}, 248.3^{\circ} \mathrm{E}$ & $\mathbf{N}$ & Zhang (1984) \\
\hline 3 & Emei & $29.6^{\circ} \mathrm{N}, 103.4^{\circ} \mathrm{E}$ & $22.9^{\circ} /+2.2^{\circ}$ & $? / 6$ & $19.5^{\circ}$ & $54.1^{\circ} \mathrm{N}, 241.8^{\circ} \mathrm{E}$ & $\mathbf{N}$ & Chan et al. (1984) \\
\hline 4 & Emei & $29.6^{\circ} \mathrm{N}, 103.4^{\circ} \mathrm{E}$ & $20.7^{\circ} /-12.6^{\circ}$ & $32 / 44$ & $4.0^{\circ}$ & $49.0^{\circ} \mathrm{N}, 251.0^{\circ} \mathrm{E}$ & $\mathbf{N}$ & $\begin{array}{l}\text { Zhao and Coe } \\
\text { (1987) }\end{array}$ \\
\hline 5 & Zhijin & $26.4^{\circ} \mathrm{N}, 105.7^{\circ} \mathrm{E}$ & $224.5^{\circ} /+30.3^{\circ}$ & $1 / 5$ & $12.0^{\circ}$ & $29.3^{\circ} \mathrm{N}, 235.3^{\circ} \mathrm{E}$ & $\mathbf{R}$ & Lin et al. (1985) \\
\hline 6.1 & Huidong & $26.7^{\circ} \mathrm{N}, 102.9^{\circ} \mathrm{E}$ & $23.0^{\circ} /-4.5^{\circ}$ & $7 / 7$ & $10.0^{\circ}$ & $53.5^{\circ} \mathrm{N}, 241.8^{\circ} \mathrm{E}$ & $\mathbf{N}$ & Huang et al. (1986) \\
\hline 6.2 & Dongchuan & $26.1^{\circ} \mathrm{N}, 103.1^{\circ} \mathrm{E}$ & $30.8^{\circ} /+5.9^{\circ}$ & $8 / 8$ & $24.9^{\circ}$ & $52.4^{\circ} \mathrm{N}, 225.9^{\circ} \mathrm{E}$ & $\mathbf{N}, \mathbf{R}$ & Huang et al. (1986) \\
\hline 6.3 & Bingchuan & $25.9^{\circ} \mathrm{N}, 100.6^{\circ} \mathrm{E}$ & $242.0^{\circ} /+1.3^{\circ}$ & $3 / 9$ & $24.8^{\circ}$ & $24.7^{\circ} \mathrm{N}, 204.3^{\circ} \mathrm{E}$ & $\mathbf{R}$ & Huang et al. (1986) \\
\hline 7.1 & Meigu, Miyi & $27.6^{\circ} \mathrm{N}, 102.4^{\circ} \mathrm{E}$ & $37.4^{\circ} /-9.6^{\circ}$ & $4 / 39$ & $30.3^{\circ}$ & $41.5^{\circ} \mathrm{N}, 228.5^{\circ} \mathrm{E}$ & $\mathbf{N}$ & Zhou et al. (1986) \\
\hline 7.2 & Miyi & $26.8^{\circ} \mathrm{N}, 101.8^{\circ} \mathrm{E}$ & $234.5^{\circ} /+22.9^{\circ}$ & $1 / 12$ & $9.0^{\circ}$ & $24.3^{\circ} \mathrm{N}, 220.6^{\circ} \mathrm{E}$ & $\mathbf{R}$ & Zhou et al. (1986) \\
\hline 8.1 & Kunming & $25.0^{\circ} \mathrm{N}, 102.7^{\circ} \mathrm{E}$ & $25.5^{\circ} /-11.9^{\circ}$ & $10 / 57$ & $6.1^{\circ}$ & $50.3^{\circ} \mathrm{N}, 241.0^{\circ} \mathrm{E}$ & $\mathbf{N}$ & This study \\
\hline 8.2 & Kunming & $25.0^{\circ} \mathrm{N}, 102.7^{\circ} \mathrm{E}$ & $244.1^{\circ} /+2.6^{\circ}$ & $1 / 2$ & - & $22.7^{\circ} \mathrm{N}, 205.8^{\circ} \mathrm{E}$ & $\mathbf{R}$ & This study \\
\hline \multicolumn{4}{|c|}{ Mean $B(1,2,3,4,6.1,6.2,7.1,8.1)$} & 8 & $5.0^{\circ}$ & $51.1^{\circ} \mathrm{N}, 241.1^{\circ} \mathrm{E}$ & $\mathbf{N}$ & $K=123.1$ \\
\hline \multicolumn{4}{|c|}{ Mean $A(5,6.3,7.2,8.2)$} & 4 & $14.9^{\circ}$ & $28.1^{\circ} \mathrm{N}, 216.6^{\circ} \mathrm{E}$ & $\mathbf{R}$ & $K=38.9$ \\
\hline \multicolumn{9}{|c|}{ Sichuan, Guizhou, and Hunan Late Permian / Early Triassic results from sedimentary rocks } \\
\hline 9 & \multicolumn{2}{|c|}{ Xuanwei Formation } & $24.0^{\circ} /-2.4^{\circ}$ & $k=15$ & - & $51.6^{\circ} \mathrm{N}, 242.7^{\circ} \mathrm{E}$ & $\mathbf{N}$ & $\begin{array}{l}\text { McElhinny et al. } \\
\text { (1981) }\end{array}$ \\
\hline 10 & \multicolumn{2}{|c|}{ Sichuan Limestones } & $35.9^{\circ} /+12.8^{\circ}$ & - & $5.3^{\circ}$ & $47.9^{\circ} \mathrm{N}, 225.1^{\circ} \mathrm{E}$ & $\mathbf{N}, \mathbf{R}$ & Heller et al. (1988) \\
\hline 11 & \multicolumn{2}{|c|}{ Shangsi GPW Section } & $36.4^{\circ} /+12.2^{\circ}$ & $k=33$ & $3.0^{\circ}$ & $47.2^{\circ} \mathrm{N}, 226.3^{\circ} \mathrm{E}$ & $\mathbf{N}, \mathbf{R}$ & Steiner et al. (1989) \\
\hline 12 & \multicolumn{2}{|c|}{ Chongging LP Section } & $37.4^{\circ} /+6.2^{\circ}$ & $k=28$ & $5.0^{\circ}$ & $45.8^{\circ} \mathrm{N}, 225.2^{\circ} \mathrm{E}$ & $\mathbf{N}, \mathbf{R}$ & Steiner et al. (1989) \\
\hline 13 & \multicolumn{2}{|c|}{ Hechuan HPT Section } & $50.4^{\circ} /+17.1^{\circ}$ & $k=34$ & $2.0^{\circ}$ & $38.5^{\circ} \mathrm{N}, 209.8^{\circ} \mathrm{E}$ & $\mathbf{N}, \mathbf{R}$ & Steiner et al. (1989) \\
\hline 14 & \multicolumn{2}{|c|}{ Hechuan HT Section } & $49.4^{\circ} /+14.9^{\circ}$ & $k=22$ & $5.0^{\circ}$ & $38.7^{\circ} \mathrm{N}, 211.8^{\circ} \mathrm{E}$ & $\mathbf{N}, \mathbf{R}$ & Steiner et al. (1989) \\
\hline 15 & \multicolumn{2}{|c|}{ Daye Formation, Hunan } & $52.5^{\circ} /+28.5^{\circ}$ & $k=47$ & $5.7^{\circ}$ & $39.8^{\circ} \mathrm{N}, 205.1^{\circ} \mathrm{E}$ & $\mathbf{N}, \mathbf{R}$ & $\begin{array}{l}\text { Dobson and Heller } \\
\text { (1993) }\end{array}$ \\
\hline 16 & \multicolumn{2}{|c|}{ C Comp., Nanxi, Changshou } & $46.1^{\circ} /+11.9^{\circ}$ & $k=84$ & $8.7^{\circ}$ & $40.0^{\circ} \mathrm{N}, 214.0^{\circ} \mathrm{E}$ & $\mathbf{N}, \mathbf{R}$ & Enkin et al. (1992) \\
\hline 17 & \multicolumn{2}{|c|}{ Maokou Formation, Guizhou } & $53.0^{\circ} /+11.0^{\circ}$ & $k=40$ & $14.7^{\circ}$ & $34.0^{\circ} \mathrm{N}, 208.0^{\circ} \mathrm{E}$ & $\mathbf{N}, \mathbf{R}$ & $\begin{array}{l}\text { Wang and Van der } \\
\text { Voo (1993) }\end{array}$ \\
\hline
\end{tabular}

$\overrightarrow{N r}$. corresponds to direction and pole labels of Figs. 1 and $10 . N=$ number of sites, $n=$ number of samples, $P=$ polarity; $K(k)$ and $A_{95}\left(\alpha_{95}\right)$ are the statistical parameters associated with the mean. 

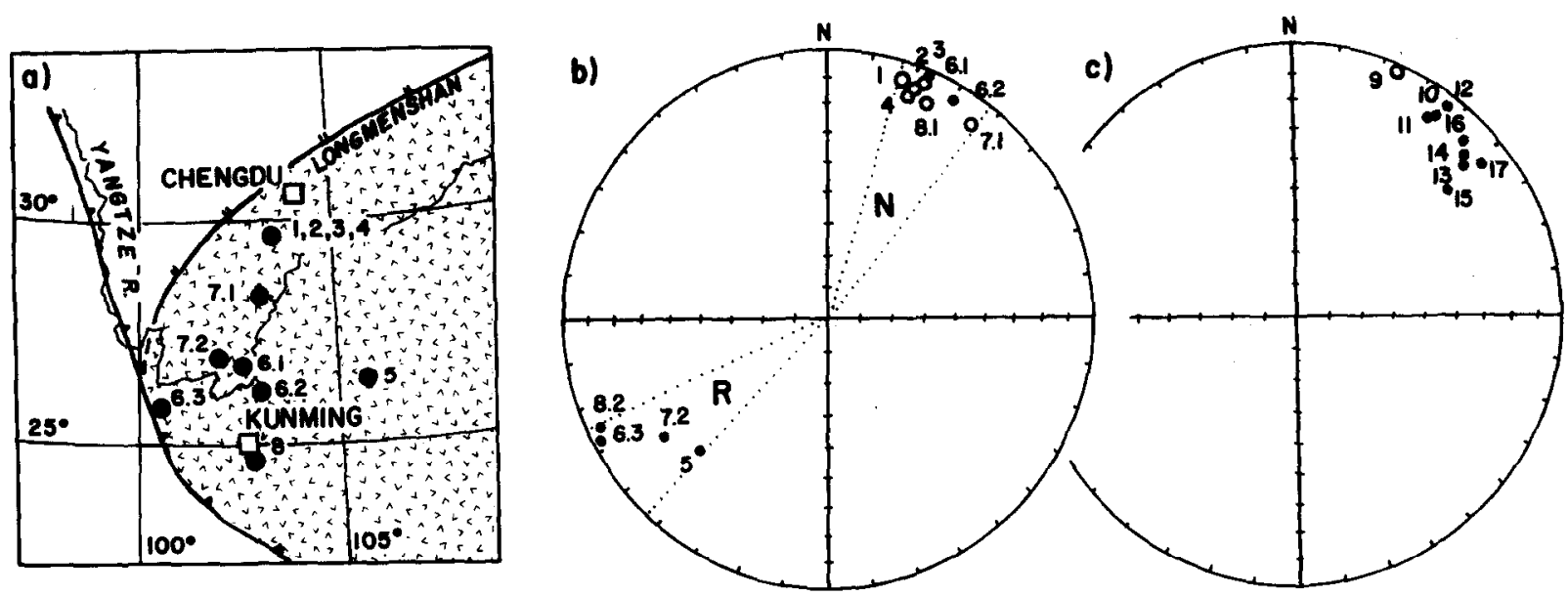

Fig. 1. (a) Sampling areas. (b) Normal and reversed-polarity directions in equal-area projection obtained from all studies of the Late Permian Emeishan Basalts. (c) Directions, all shown as normal polarity, for sedimentary rocks of Late Permian to Early Triassic age of the South China Block (SCB). Open (closed) symbols represent upper (lower) hemisphere projections. Studies are labeled by numbers identified in Table 1 .

appears to be younger (more towards the present-day pole) than the paleopole calculated for the reversed rocks (e.g., Table 1 ).

In order to contribute towards a resolution of these issues, we have collected 59 samples from 10 sites in the vicinity of Kunming (Fig. 1a). We also collected Carboniferous and Permian carbonates in this area, but have found that they are completely remagnetized in a recent geomagnetic field. The basalt localities are geographically spread and significantly distant from either the Longmenshan Fault or the Sichuan sampling sites, so that we can test for relative rotations. Moreover, the basalt flows show varying dips at our sites due to folding in the Tertiary, so that we can apply a fold test. We have also been fortunate enough to observe a few reversed-polarity samples which allow us to address their mineralogical relations and, in turn, the possibilities of remagnetization through alteration.

\section{Geology and sampling}

The widespread Emeishan eruptives are plateau basalts of Longtanian (Late Permian) age, which correlates with the latest Kazanian (Guadalupian) to early Tatarian (Ochoan) Late Permian stages of the western world (Yang et al., 1986). The DNAG timescale (Palmer, 1983) assigns an age of about $253 \mathrm{Ma}$ to the Kazanian-
Tatarian boundary, which falls well within the age span in which dual-polarity (i.e., post-Kiaman) magnetizations have been observed elsewhere (e.g., Creer et al., 1971; Molina-Garza et al., 1989; Haag and Heller, 1991). The basalts are overlain by the fossiliferous Xuanwei and Feixianguan Formations of latest Permian and Early Triassic ages; these formations or their stratigraphic equivalents in Sichuan Province have yielded paleopoles in the studies by McElhinny et al. (1981), Chan et al. (1984), Heller et al. (1988), Steiner et al. (1989), and Enkin et al. (1992). Dobson and Heller (1993) studied the paleomagnetism of the Early-Middle Triassic Daye and Jialingiang formations in Hunan Province. The basalts are underlain by the fossiliferous Kungurian-Kazanian Maokou or Qixia formations; the paleomagnetism of the Maokou Formation has been studied by Wang and Van der Voo (1993). Isotopic ages for the basalts are variable and fall around $236 \mathrm{Ma}$ (Zhou et al., 1986), which is somewhat too young; ages as young as $167 \mathrm{Ma}$ near Zhijin have led Lin (1989) to argue for partial to complete isotopic resetting and remagnetization.

The outcrop area of the basalts, thought to record a rifting stage in the Late Permian, is approximately $40,000 \mathrm{~km}^{2}$ as a remnant of what may well have been a covered area that was ten times larger. The average thickness is $700 \mathrm{~m}$, with 
a maximum of $5384 \mathrm{~m}$ (Lin, 1985). Near Kunming $\left(25^{\circ} \mathrm{N}, 102.7^{\circ} \mathrm{E}\right)$ we drilled at ten sites from fresh roadcuts with orientation by magnetic compass. The outcrops generally consist of thick sequences of monotonous and structureless lava flows, with the rocks having a very dark grey to green, dense, amygdoidal and aphyric appearance. Determination of the bedding orientations was possible because of sedimentary (albeit weathered) layers in the vicinity of the basalts.

\section{Paleomagnetic results}

Intensities of natural remanent magnetizations (NRM) range from 1 to $15 \mathrm{~A} / \mathrm{m}$. Pilot alternating field (AF) and thermal demagnetization techniques showed that AF effectively reduces the intensity to zero in fields up to $100 \mathrm{mT}$, but that

\section{E853}

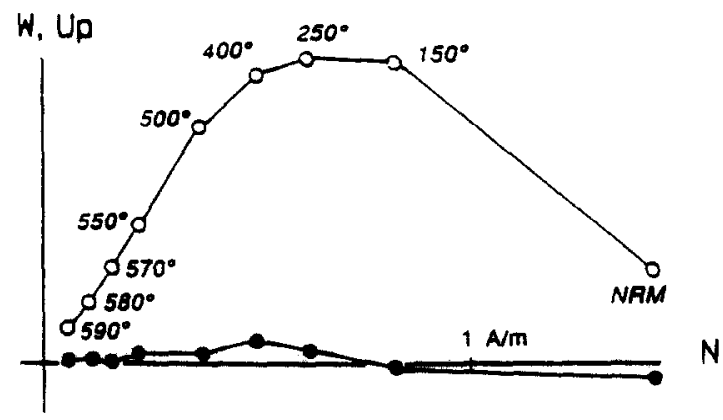

\section{E433}

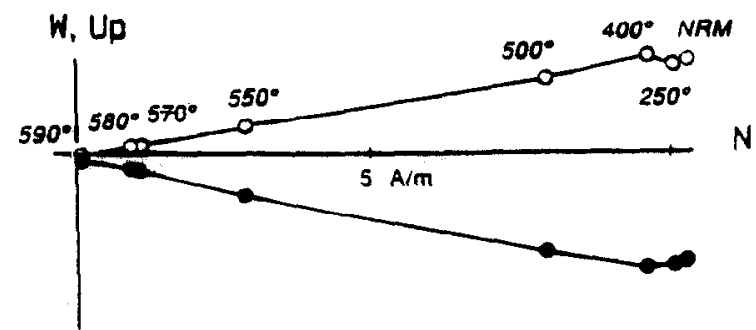

Fig. 2. Representative orthogonal demagnetization diagrams (Zijderveld, 1967) of normal-polarity Emeishan samples in geographic coordinates. Plotted points represent the endpoints of the magnetization vector during progressive thermal demagnetization; open (closed) symbols represent projections onto the vertical (horizontal) plane. The intensity of magnetization is indicated along the axes. thermal treatment was preferable because it provided better resolution of the demagnetization trajectories. Thermal demagnetization revealed only one component of magnetization, occasionally after removal of a northerly and intermediate down present-day field overprint (Fig. 2). The characteristic directions of magnetization are $\mathrm{N}$ to NE and shallowly down to intermediate up and are listed in Table 2.

Figure 3 illustrates one normal and two reversed characteristic directions of magnetization from the same site (32); the reversed directions are SW and shallowly down. The outcrop situation did not give any indications that different flows were present, but at the time of sampling (not knowing that there would be a reversal here) subtle flow distinctions may have escaped attention.

Correction for the tilt of the flows (Fig. 4) illustrates that the fold test is positive at the $99 \%$ confidence level according to McElhinny (1964). A well-grouped mean is obtained in stratigraphic coordinates (Table 2) with $k 2=64$ and $\alpha_{95}=6^{\circ}$, whereas these values are $k 1=9$ and $\alpha_{95}=17^{\circ}$ before tilt correction. The magnetizations clearly predate Tertiary folding.

\section{The failed reversal tests}

We have mentioned earlier that the normal and reversed directions of magnetization from other studies are not antipodal (Fig. 1b, Table 1) and that this has led some workers to argue for remagnetization of (part of?) the Emeishan Basalts. In our study, we observe the same phenomenon (Table 2), although admittedly we have only two samples that show reversed directions. However, these two samples occur in a site that also shows normal directions in 5 samples. The fact that these normal directions are in agreement with the mean directions from all our other normal-polarity sites indicates that relative rotations are not a viable explanation for the non-antipodality. The agreement of the normal-polarity directions from Sichuan and Yunnan (Fig. 1b) and, to a lesser degree, also between the reversed polarity directions from Sichuan (Huang et al., 1986; Zhou et al., 1986), Guizhou (Lin et al., 


\section{TABLE 2}

Paleomagnetic results from this study

\begin{tabular}{|c|c|c|c|c|c|c|c|}
\hline \multirow[t]{2}{*}{ Site } & \multirow[t]{2}{*}{ Strike/dip } & \multirow[t]{2}{*}{$n / N$} & \multicolumn{2}{|l|}{ Decl/Incl } & \multirow[t]{2}{*}{$k$} & \multirow[t]{2}{*}{$\alpha_{95}$} & \multirow[t]{2}{*}{ Pole position } \\
\hline & & & In situ & Tilt corrected & & & \\
\hline 17 & $19 / 60$ & $5 / 5$ & $41.4^{\circ} /+1.2^{\circ}$ & $31.4^{\circ} /-18.0^{\circ}$ & 321 & $4.3^{\circ}$ & \\
\hline 18 & $34 / 48$ & $5 / 5$ & $46.0^{\circ} /-1.6^{\circ}$ & $42.5^{\circ} /-8.6^{\circ}$ & 121 & $7.0^{\circ}$ & \\
\hline 32 & $99 / 6$ & $5 / 7$ & $35.0^{\circ} /-19.5^{\circ}$ & $34.0^{\circ} /-13.7^{\circ}$ & 139 & $6.5^{\circ}$ & \\
\hline $32 *$ & $99 / 6$ & $2 / 7$ & $245.0^{\circ} /+6.0^{\circ}$ & $244.1^{\circ} /+2.6^{\circ}$ & - & - & $22.7^{\circ} \mathrm{N}, 205.8^{\circ} \mathrm{E}$ \\
\hline 90 & $204 / 55$ & $9 / 9$ & $12.6^{\circ} /-11.7^{\circ}$ & $27.3^{\circ} /-15.9^{\circ}$ & 142 & $4.3^{\circ}$ & \\
\hline 91 & $181 / 29$ & $3 / 3$ & $25.0^{\circ} /-14.3^{\circ}$ & $28.7^{\circ} /-1.5^{\circ}$ & 608 & $5.0^{\circ}$ & \\
\hline 92 & $204 / 45$ & $8 / 8$ & $20.4^{\circ} /-8.0^{\circ}$ & $27.2^{\circ} /-8.2^{\circ}$ & 157 & $4.4^{\circ}$ & \\
\hline 167 & $134 / 56$ & $5 / 5$ & $344.9^{\circ} /-59.6^{\circ}$ & $17.2^{\circ} /-15.5^{\circ}$ & 266 & $4.7^{\circ}$ & \\
\hline 168 & $149 / 48$ & $5 / 5$ & $355.0^{\circ} /-46.6^{\circ}$ & $19.3^{\circ} /-15.2^{\circ}$ & 473 & $3.5^{\circ}$ & \\
\hline 169 & $124 / 45$ & $5 / 5$ & $355.5^{\circ} /-47.1^{\circ}$ & $8.6^{\circ} /-8.1^{\circ}$ & 104 & $6.6^{\circ}$ & \\
\hline 171 & $135 / 24$ & $7 / 7$ & $16.4^{\circ} /-32.3^{\circ}$ & $20.7^{\circ} /-10.8^{\circ}$ & 126 & $5.4^{\circ}$ & \\
\hline \multicolumn{8}{|l|}{ Mean } \\
\hline & & $10 / 10$ & $21.0 /-24.0$ & & 9.1 & 17.0 & $46.9 \mathrm{~N}, 252.8 \mathrm{E}$ \\
\hline & & & & $25.5 /-11.9$ & 63.5 & 6.1 & $50.3 \mathrm{~N}, 241.0 \mathrm{E}$ \\
\hline
\end{tabular}

Strike follows the left-hand rule, such that it is the dip direction minus $90^{\circ} . n=$ number of samples used in the statistical analysis and $N=$ number of samples demagnetized.

* Indicates the reversed-polarity directions of site 32 (not included in the formation mean).

1985) and Yunnan (this study), shows that neither local nor regional rotations about vertical axes have been significant.

\section{E255}

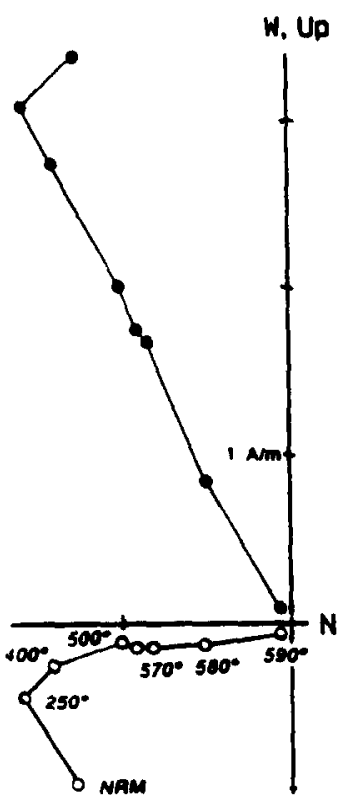

\section{E256}

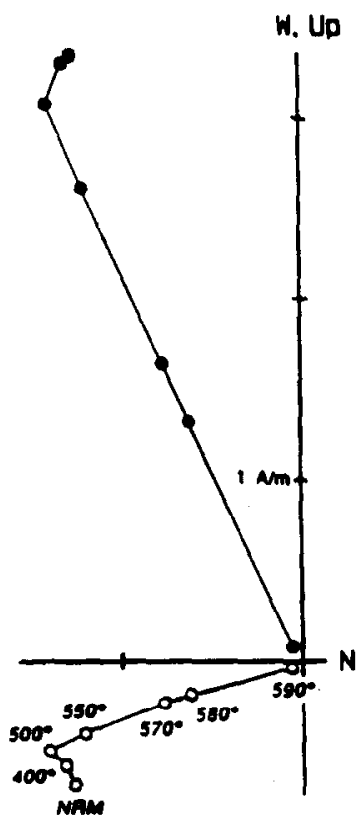

Other possible explanations for the non-antipodal declinations involve an examination of possibly incomplete demagnetizations, non-dipole

Fig. 3. Orthogonal demagnetization diagrams of reversed and normal-polarity Emeishan samples from site 32 in geographic coordinates. For further explanation see Fig. 2. 

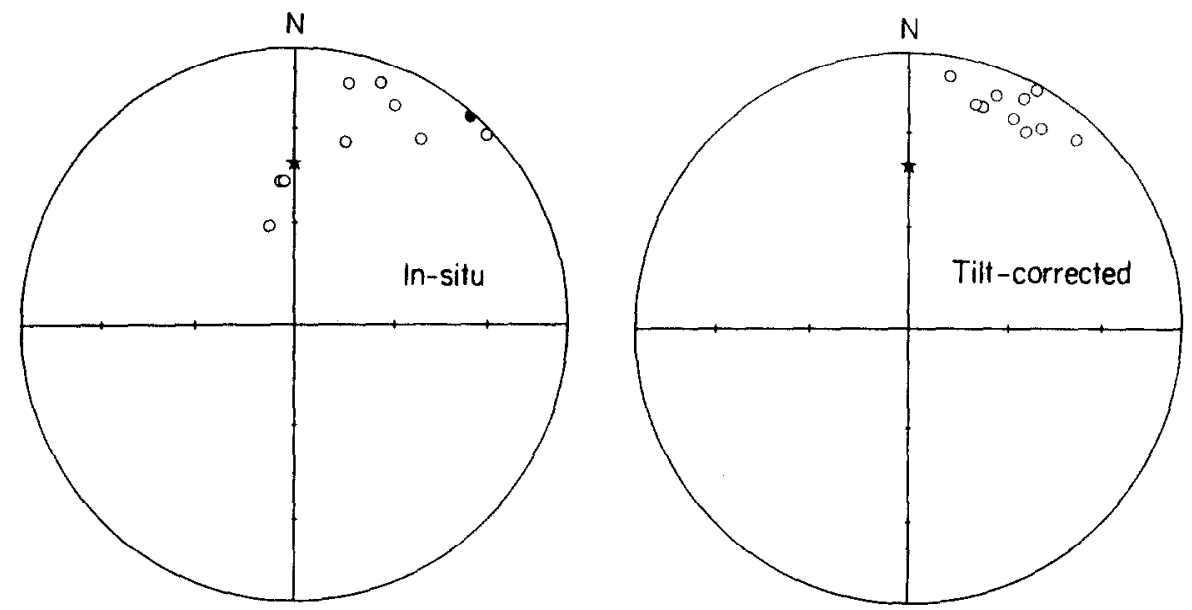

Fig. 4. Equal-area projection (as in Fig. 1) of the site-mean directions of this study before and after tilt correction.

fields or asymmetric reversals in the Late Permian, errors in sample orientation, or later remagnetization represented by one or the other polarity group. Incomplete demagnetization, i.e., incomplete removal of present-day field over-
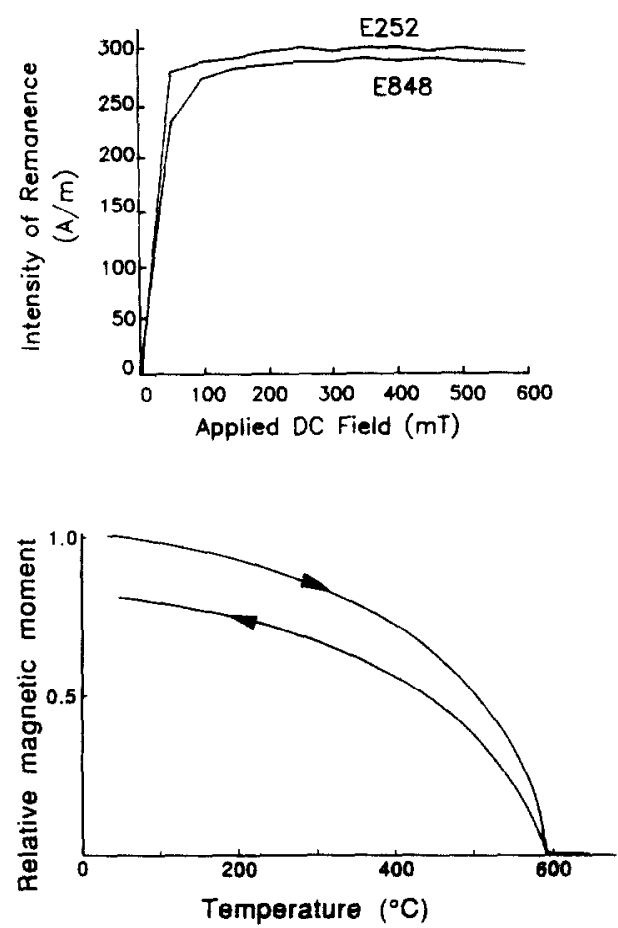

Fig. 5. Top: acquisition of isothermal remanent magnetization (IRM) of two representative basalt samples, indicating the rapid saturation indicative of magnetite. Bottom: thermomagnetic analysis of a powdered basalt sample, indicating Curie temperatures of titanium-poor magnetite. The strength of the applied field was $1.1 \mathrm{~T}$. prints, is not indicated by published demagnetization diagrams, nor in the results of this study shown in Figures 2 and 3. The trajectories obtained in thermal demagnetization are perfectly linear and decay straight to the origin without any hint of a high unblocking-temperature component, suggesting that the normal or reversed components are unlikely to be composite.

Explanations involving non-dipole fields, secular variation or asymmetric reversals (e.g., Pesonen and Halls, 1983), are difficult to test with rocks from China alone. However, secular variation as an explanation can be ruled out because the entire range of declinations observed in the basalts has now also been observed in Permian and Triassic sedimentary rocks (Fig. 1c). Such geomagnetic field features as long-term non-dipole fields and asymmetric reversals must be global phenomena and we note that other studies of rocks of late Kazanian-early Tatarian age (e.g., Molina-Garza et al., 1989) show well-defined antipodal reversals. While an asymmetric Late Permian reversal pattern remains an ad-hoc possibility, we believe that it is more fruitful to examine other possible explanations first.

The possibility of orientation errors exists for those studies that employed a magnetic compass for sample orientation; to our knowledge all studies reporting (some) reversed-polarity directions, including our own, fall in this category. Our own sampling techniques included sighting of distant objects and readings at various distances from the 


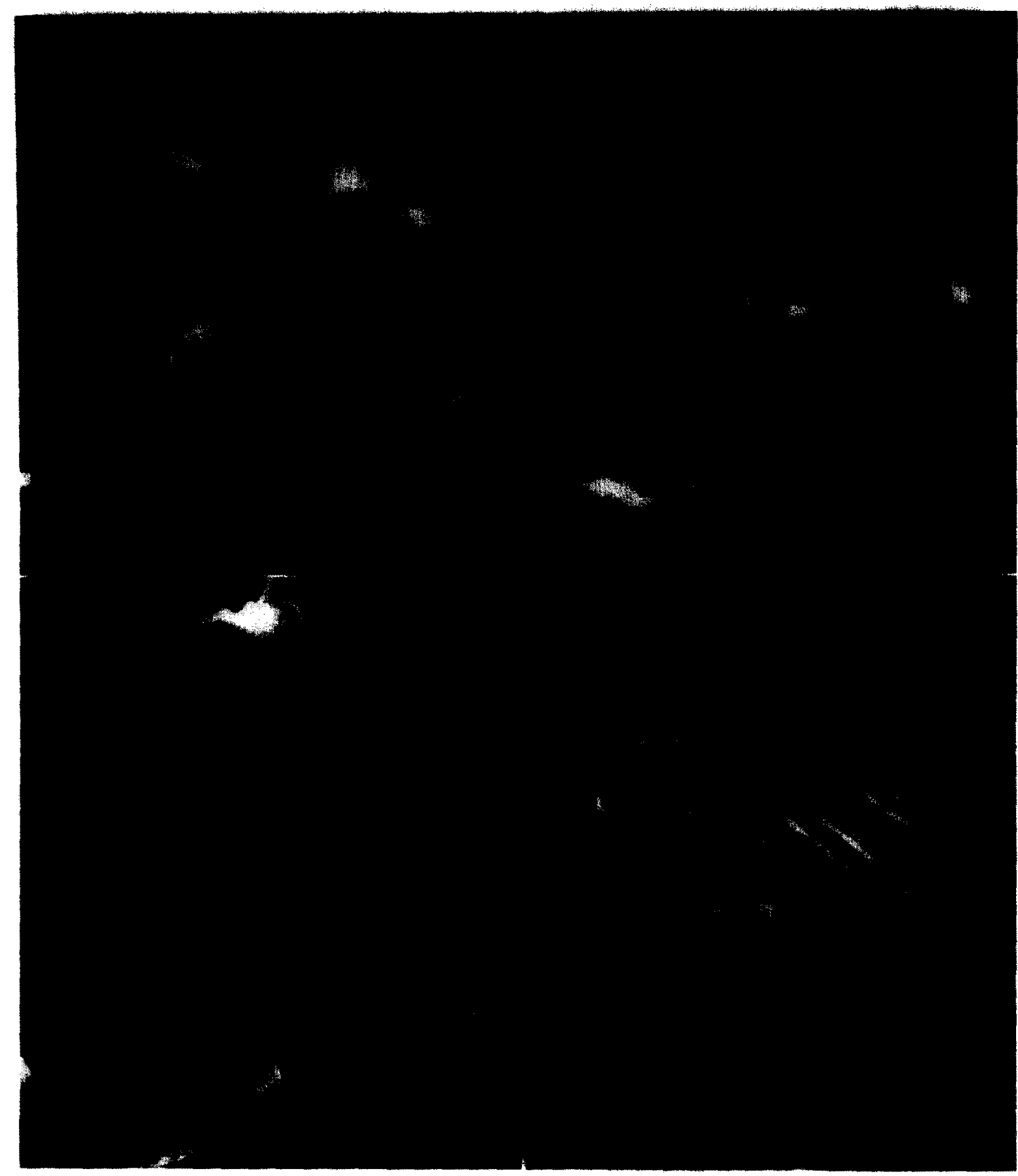

Fig. 6. SEM images of iron-oxide grains in two samples from the Emeishan basalts with SW-NE declinations. $P l=$ Plagioclase; $P x=$ Pyroxene; $Q=$ Quartz; $C h=$ Chlorite. (a) Cruciform titaniferous iron oxide grains in a cavity perched on chlorite surrounded by plagioclase and quartz; secondary electron image (SEI) from a reversed-polarity sample (E255). (b) Dendritic and cruciform titaniferous iron oxide grains in a cavity associated with chlorite, pyroxene and plagioclase, SEI from a reversed-polarity sample (E255). (c) Cruciform titaniferous iron oxide grains in plaginclase, SEI from a reversed-polarity sample (E25S). (d) Dendritic and cruciform titaniferous iron oxide grains in and adjacent to plagioclase, pryoxene and quartz, SEI from a normal-polarity sample (E252). 


\section{Counts}
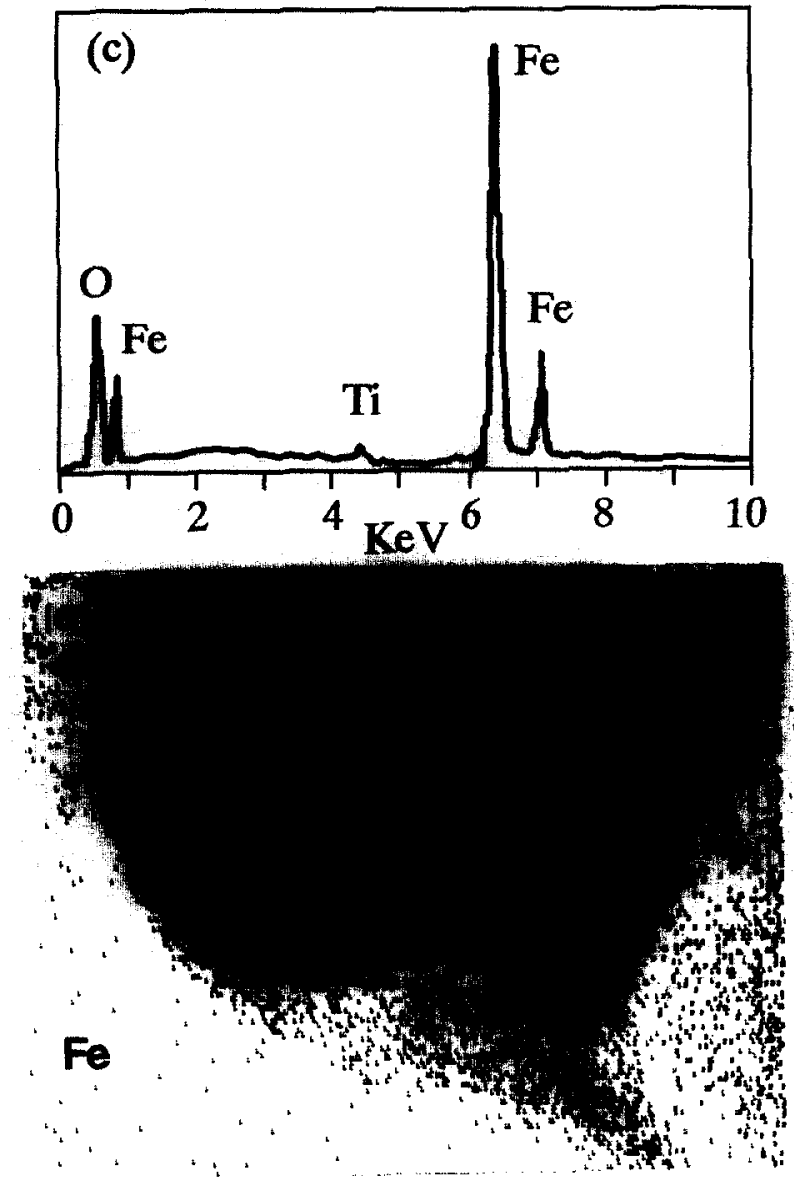

\section{Counts}
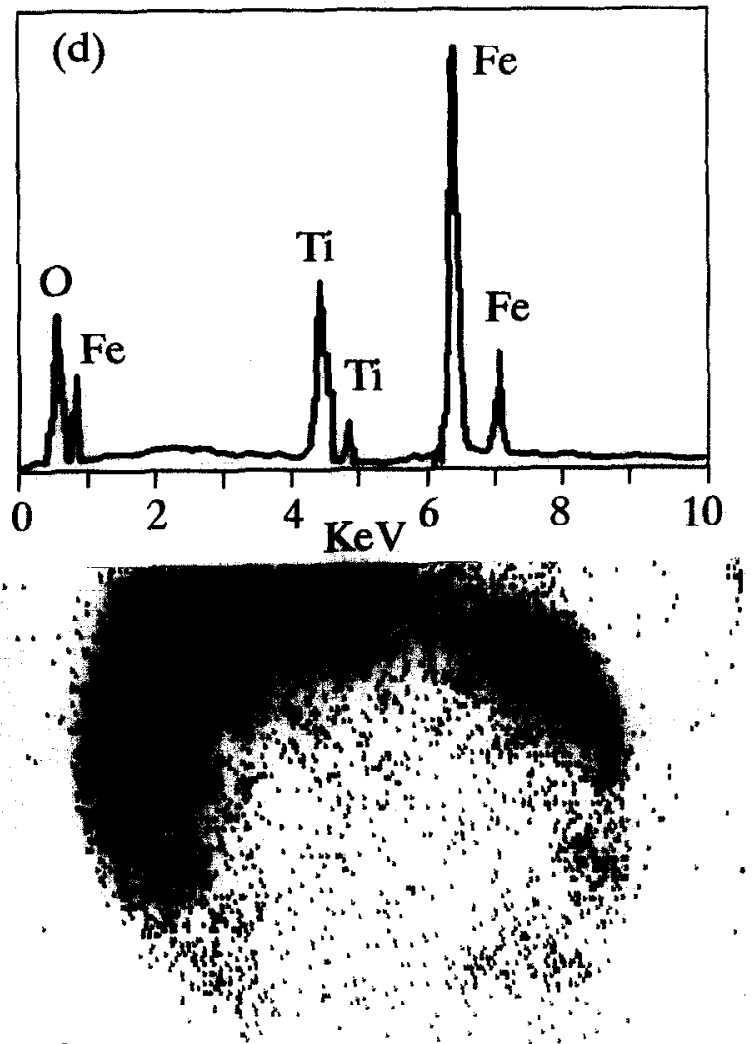

$\mathrm{Ti}$ 
outcrop: this test for local magnetic effects did not reveal any differences. Moreover, the studies of McElhinny et al. (1981) and Zhao and Coe (1987) used a solar compass, and given the similarity of their results to the normal mean directions from the other studies (see Fig. 1b), it is very likely that at least the normal-polarity directions are not affected by systematic orientation errors.

This leaves the possibility of remagnetization, which can be examined by looking at the magnetic carriers.

\section{Rock magnetic experiments and electron mi- croscopy}

Unblocking temperatures (e.g., Figs, 2 and 3) are all less than $590^{\circ} \mathrm{C}$ and typical coercivities in AF demagnetization are less than $100 \mathrm{mT}$, suggesting magnetite as the carrier of magnetization. This is confirmed by acquisition of isothermal remanent magnetization (IRM) and Curie temperature runs on a horizontal balance (Fig. 5). Some alteration (probably oxidation) took place during heating, causing the thermomagnetic curve to be irreversible.

Optical microscope observations of eight polished thin-sections reveal plagioclase (about $80 \%$ by volume), pyroxene, opaques and glassy groundmass. Partial alteration of plagioclase and pyroxene has produced chlorite, sericite and other clay minerals. Opaque grains are typically less than $2 \mu \mathrm{m}$ in size but abundant (up to $5 \%$ by volume). Because the optically detectable opaque mineral grains are very small, and in order to determine if sub-optical scale magnetic phases are present, scanning electron microscope (SEM) and scanning transmission electron microscope (STEM) observations were carried out. The SEM and STEM that were used are Hitachi S-570 and
Philips CM-12 instruments, respectively; both are equipped with Kevex Quantum energy dispersive analysis (EDA) systems. The only iron-oxides detectable with both SEM and STEM were those that were also detected optically; our observations can be divided into two groups, one showing titaniferous (primary) magnetite and the other showing pure (secondary) magnetite as an alteration product. These two groups of observations will be discussed sequentially below.

In two samples, the magnetite has very characteristic shapes, ranging from cruciform (Fig. 6a) to dendritic (Fig. 6b) in outline. Such shapes are diagnostic of crystals that are in the early stages of growth and that have been quenched. They occur within plagioclase grains (Fig. 6c,d) but more commonly are on or at contacts with pore space (Fig. 6a,b) that is inferred to have been caused by vapor at high temperature.

A dendritic shaped iron-oxide grain was prepared for STEM observations (Fig. 7a). Selected area electron diffraction (SAED) patterns (Fig. 7b) verified that the crystals have the single-crystal magnetite structure. EDA spectra (Fig. 7c,d) showed that they are titaniferous. Although the analyses are only qualitative, they show that magnetite varies from being nearly Ti-free (Fig. 7c) to having ulvöspinel $\left(\mathrm{TiFe}_{2} \mathrm{O}_{4}\right)$ components of greater than $50 \%$ (Fig. $7 \mathrm{~d}$ ). Such a range in composition occurs within single crystals, as shown in the X-ray mapping of $\mathrm{Fe}$ and $\mathrm{Ti}$ (Fig. 7e), demonstrating a lack of equilibrium as consistent with quenching from high temperatures where crystallization occurred rapidly. The SAED patterns of titaniferous magnetite are those of a single crystal, demonstrating the lack of exsolution of ulvöspinel and/or ilmenite, as verified by the absence of lamellae in TEM images. Such single-phase titaniferous magnetite may form only at high temperatures that exceed the temperature

Fig. 7. STEM observations of dendritic titaniferous iron oxide of the Emeishan basalt revealing reversed-polarity paleomagnetic directions (sample E255). (a) A scanning image of dendritic titaniferous iron oxide grains, SEI. (b) Selected area electron diffraction (SAED) pattern of grains in (a), diagnostic of a single-crystal magnetite based on the indexed reflections. (c) An energy dispersive analysis (EDA) spectrum obtained from a grain in (a), showing nearly Ti-free iron oxide composition. (d) An EDA spectrum of iron oxide with more than $50 \%$ of ulvöspinel component. (e) X-ray mapping of $\mathrm{Fe}$ and $\mathrm{Ti}$ distribution in the grain at the lower left side of (a). 

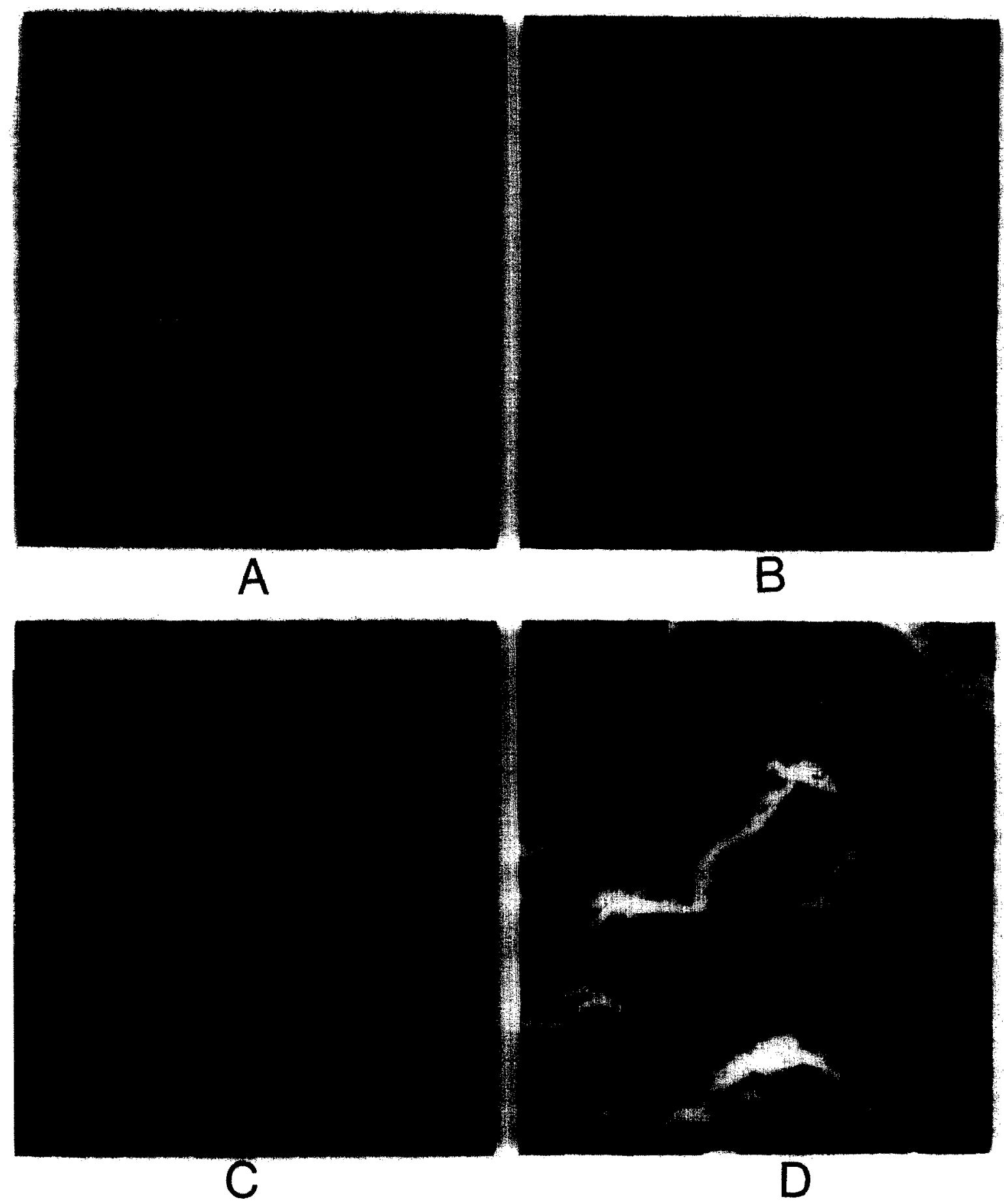

Fig. 8. SEM images of polished thin-sections of two Emeishan basalt samples revealing a northerly normal-polarity paleomagnetic direction (samples 848, 865); back-scattered electron images (BEI). (A) Relict of a cruciform titanomagnetite crystal replaced by Ti-free magnetite (brighter areas) and sphene ( $S P H$, medium dark areas), surrounded by pyroxene ( $P x$ ), $\mathrm{K}$-feldspar ( $K$ ) and chlorite $(C L)$ in sample 848 . (B) Plagioclase ( $P L)$ grain, rimmed by magnetite (bright edge) and containing sphene (Sph) patches, adjacent to chlorite (sample 848), (C) Relict of a cruciform titanomagnetite crystal replaced by Ti-free magnetite (brighter areas) and sphene (Sph, medium dark areas), with chlorite (sample 865): (D) Chlorite with magnetite inclusions surrounded by anhedral sphene (sample 865). Scale bars: (A) $30 \mu \mathrm{m}$, (B) $8 \mu \mathrm{m}$, (C,D) $15 \mu \mathrm{m}$. 
of the magnetite-ulvöspinel solvus, with rapid cooling from that level. We interpret these observations to collectively demonstrate that the carrier of magnetization is magnetite with variable Ti content that has a primary origin derived from rapid cooling (Evans and Wayman, 1972; Haggerty, 1976; Wayman and Evans, 1977). Two samples, one with normal-polarity (252) and one with reversed-polarity (255), show these shapes, textures and mineralogies (see caption Fig. 6).

Six other samples show the second pattern and contained magnetite with no detectable $\mathrm{Ti}$, or very small quantities of $\mathrm{Ti}$; only one sample of this group contained magnetite with appreciable Ti, but even in that sample such magnetite was associated with Ti-free magnetite. Magnetite with two kinds of textures was observed: (1) As shown in Figure 8 a,c, magnetite with a cruciform shape was commonly associated with sphene (medium dark areas) occurring in a matrix of chlorite, pyroxene and plagioclase. (2) Some samples were dominated by magnetite having non-cruciform, anhedral to subhedral shapes, as shown in Figure $8 \mathrm{~b}, \mathrm{~d}$. Such magnetite was intimately associated with sphene and chlorite. We infer that the pure magnetite and sphene formed as alteration products of primary igneous (sometimes cruciform)

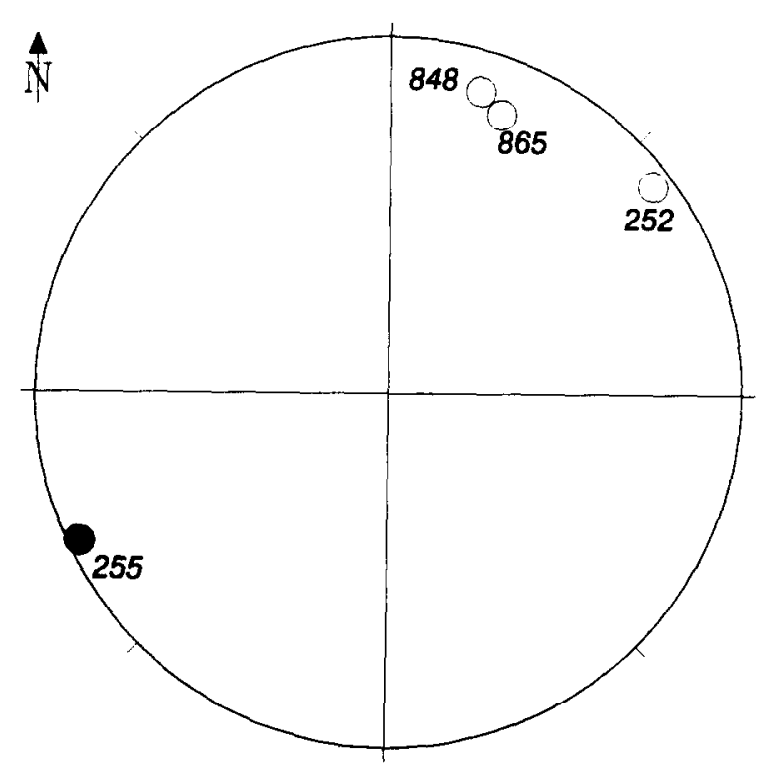

Fig. 9. Paleomagnetic directions obtained from the four samples on which the SEM observations of Figs. 6-8 were made (see text for discussion). titanomagnetite, of the kind shown in Figure 6. In the case of one sample, the original igneous texture was largely replaced by one dominated by chlorite. Such alteration at relatively low temperatures of titanomagnetite to Ti-free magnetite and sphene is common (e.g., Shau et al., 1993), and generally associated with alteration of primary Mg-silicates to chlorite. All samples that were observed to contain magnetite with little or no Ti showed normal-polarity NNE directions.

A total of eight samples was examined by SEM. Their directions fall in two groups and can be directly correlated with the two patterns of magnetite. The directions of the four samples shown in Figures 6 and 8 are shown in Figure 9. Samples 252 and 255 show primary (titano-)magnetite and NE-SW directions, whereas samples 848 and 865 show secondary magnetite and NNE directions. A comparison with Figure 1 reveals that the reversed-polarity directions are all similar to those of the samples with primary (titano-)magnetite. The normal-polarity directions of Figure 1 conform to those of the samples with secondary magnetite, or they may show directions in between with declinations ranging from 15 to $40^{\circ}$.

\section{Discussion}

A well-defined characteristic normal-polarity magnetization has been observed in the Emeishan Basalts around Kunming, Yunnan Province. The magnetization is older than the Tertiary folding. Agreement between our directions and those previously obtained in northern Yunnan and Sichuan provinces argues against hypothetical rotations about vertical axes on a local or regional scale, such as suggested by Lin et al. (1985) and McElhinny (1985), unless, of course, these rotations occurred before the Emeishan magnetization was acquired.

Only two samples show reversed polarity with a declination around $240^{\circ}$. However, one of these samples as well as one normal-polarity sample with a nearly antipodal declination of about $50^{\circ}$ reveal primary (titano-)magnetite as the carrier of magnetization. In contrast, samples with the more northerly declinations have a magnetization carried by secondary magnetite. 
Pole positions calculated from the normalpolarity directions of the Emeishan Basalts are shown as open circles in Figure 10 as a cluster labeled Group $B$; individual results are labeled according to the symbols listed in Table 1 . The four Emeishan pole positions clustered in Group $A$ are based on reversed-polarity directions and are significantly different from those of Group $B$; this difference reflects, of course, the non-antipodal nature of the magnetizations and the failed reversal test.

The normal-polarity Group $B$ poles are more likely candidates for a "less-reliable" label than the poles of Group $A$ in Figure 10, given our SEM observations of the alteration of original titanomagnetite to pure magnetite plus sphene in Group $B$ samples. Moreover, the pole positions of Group $B$ look "younger", i.e., closer to the north pole on the apparent polar wander path for the South China Block than the Group $A$ poles from the basalts. At the same time, the latter are based on fewer directions and their reliability has not been enhanced by positive field tests. Dualpolarity directions and paleopoles obtained from sediments of Late Permian to Early Triassic age (McElhinny et al., 1981; Heller et al., 1988; Steiner et al., 1989; Dobson and Heller, 1992; Enkin et al., 1992; Wang and Van der Voo, 1993) appear to agree more with the poles of Group $A$ (see Table 1, Fig. 1c, Fig. 10, triangles).

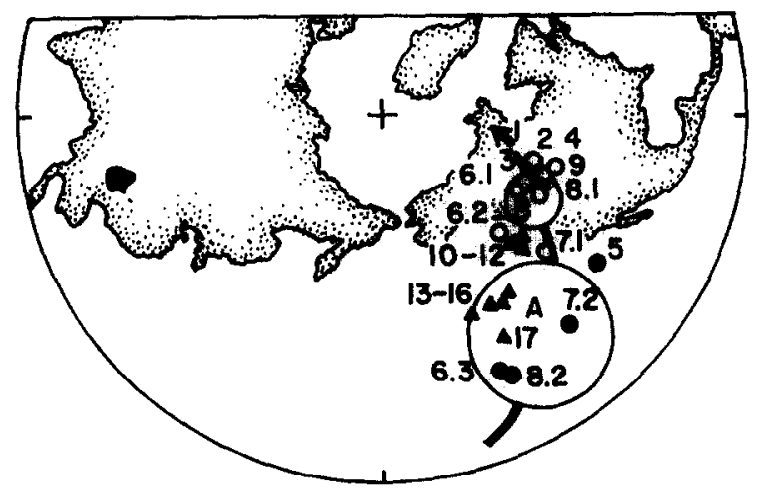

Fig. 10. Late Permian paleopoles for the Emeishan Basalts. Cluster $B$ is a mean with cone of $95 \%$ confidence based on normal polarity results $(O)$; Cluster $A$ represents reversed polarities $(\bullet)$. Paleopoles obtained from sedimentary rocks of Late Permian-Early Triassic age are shown as closed triangles. Numbers correspond to Table 1. Black area in China indicates the sampling localities.
It is argued here that the more abundant Group $B$ poles of the Emeishan Basalts represent a magnetization that is younger than the age of the rocks, whereas the group $A$ poles may be Late Permian in age. The SEM observations of this study show that the Group $B$ (rc-)magnetization in our samples is due to alteration that was likely hydrothermal in origin. The age of this remagnetization remains uncertain; judging from other paleopole results for the South China Block, this age appears to be Triassic to Early Jurassic(?).

\section{Acknowledgments}

We thank the reviewers, $M$. Kono and F. Heller, for very valuable comments. This study was supported by grants from the Geological Society of America (H.T. Stearns Award to W. Fang), the Scott Turner Fund of the University of Michigan, and by the Yunnan Institute of Geological Sciences. Electron microscopy work was partly supported by the R.B. Mitchell Fund of the University of Michigan and all of the laboratory work was supported by the Division of Earth Sciences, the National Science Foundation, grants EAR 88-16772 and EAR 89-15705.

\section{References}

Chan, L.S., Wang, C.Y. and Wu, X.Y., 1984. Paleomagnetic results from some Permian-Triassic rocks from snuthwestern China. Geophys. Res. Lett., 11: 1157-1160.

Creer, K.M., Mitchell, J.G. and Valencio, D.A., 1971. Evidence for normal geomagnetic field polarity at $263 \pm 5$ m.y. B.P. within the late Paleozoic reversed interval. Nature, 233: $87-89$

Dobson, J.P. and Heller, F., 1993. Triassic paleomagnetic results from the Yangtze Block, SE China. Geophys. Res. Lett., in press.

Enkin, R.J., Courtillot, V., Leloup, H., Yang, Z., Xing, L., Zhang, J. and Zhuang, Z., 1992. The paleomagnetic record of Uppermost Permian, Lower Triassic rocks from the South China Block. Geophys. Res. Lett., 12: 2147-2150.

Evans, M.E. and Wayman, M.L., 1972. The Mid-Atlantic Ridge near $45 \mathrm{~N}$. XIX. An electron microscope investigation of the magnetic minerals in basalt samples. Can. $J$. Earth Sci., 9: 671-678.

Haag, M. and Heller, F., 1991. Late Permian to Early Triassic magnetostratigraphy. Earth Planet. Sci. Lett., 107: 42-54.

Haggerty, S.E., 1976. Opaque mineral oxides in terrestrial igneous rocks. In: D. Rumble (Editor), Oxide Minerals. 
Mineral. Soc. Am. Short Course Notes, Washington, DC, pp. $\mathrm{Hg}$ 101-171.

Heller, F., Lowrie, W., Li, H.M. and Wang, J.D., 1988. Magnetostratigraphy of the Permo-Triassic boundary section at Shangsi (Guangyuan, Sichuan Province, China). Earth Planet. Sci. Lett., 88: 348-356.

Huang, K.N., Opdyke, N.D., Xu, G.Z. and Tang, R.L., 1986. Further paleomagnetic results from the Permian Emeishan basalt in SW China. Kexue Tongbao, 31: 1195-1201.

Lin, J.L., 1989. Comment on the Permian paleomagnetic results from South China. Geol. Rev., 35: 349-354 (in Chinese with English abstract).

Lin, J.L., Fuller, M.D. and Wang, W.Y., 1985. Preliminary Phanerozoic polar wander paths for the North and South China blocks. Nature, 313: 444-449.

Lin, J.Y., 1985. Spatial and temporal distribution and other geological characters of the Permian basaltic rocks in the three provinces of southwestern China. Kexue Tongbao, 12: 929-932 (in Chinese).

MacDonald, W.D., 1980. Net rotation, apparent tectonic rotation, and the structural correction in paleomagnetic studies. J. Geophys. Res., 85: 3659-3669.

McElhinny, M.W., 1964. Statistical significance of the fold test in paleomagnetism. Geophys. J.R. Astron. Soc., 8: 338-340.

McElhinny, M.W., 1985. Permian paleomagnetism of the western Yangtze Block, China: a reinterpretation. J. Geodyn., 2: 115-117.

McElhinny, M.W., Embleton, B.J.J., Ma, X.H. and Zhang, X.K., 1981. Fragmentation of Asia in the Permian. Nature, 293: 312-316.

Molina-Garza, R.S., Geissman, J.W. and Van der Voo, R., 1989. Paleomagnetism of the Dewey Lake Formation (Late Permian), northwest Texas: end of the Kiaman superchron in North America. J. Geophys. Res., 94: 17881-17888.

Palmer, A.R., 1983. The decade of North American geology (DNAG) 1983 geologic time scale. Geology, 11: 503-504.
Pesonen, L.J. and Halls, H.C., 1983. Geomagnetic field intensity and reversal asymmetry in late Precambrian $\mathrm{Ke}$ weenawan rocks. Geophys. J.R. Astron. Soc., 73: 241-270.

Shau, Y.-H., Peacor, D.R. and Essene, E., 1993. Formation of magnetic single-domain magnetite in ocean-ridge basalts with implications for sea-floor magnetism. Science, submitted.

Steiner, M.B., Ogg, J.G., Zhang, Z. and Sun, S., 1989. The Late Permian-early Triassic magnetic polarity time scale and plate motions of South China. J. Geophys. Res., 94: $7343-7363$.

Wang, Z. and Van der Voo, R., 1993. Rapid apparent polar wandering of South China during the latest Paleozoic and early Mesozoic: A paleomagnetic study of Upper Permian limestones from Guizhou Province. Tectonophysics, submitted.

Wayman, M.L. and Evans, M.E., 1977. Oxide microstructures and the magnetic properties of Leg 37 basalts. Can. J. Earth Sci., 14: 656-663.

Yang, Z.Y., Cheng, Y.Q. and Wang, H.Z., 1986. The Geology of China. Oxford Monogr. Geol. Geophys., 3. Clarendon, Oxford, 303 pp.

Zhang, Z.K., 1984. Sino-Korean blocks and Yangtze block as part of the Pacifica continent in the late Paleozoic. Bull. Chin. Acad. Sci., 9: 45-54 (in Chinese with English abstract).

Zhao, X.X. and Coe, R., 1987. Paleomagnetic constraints on the collision and rotation of North and South China. Nature, 327: 141-144.

Zhou, Y.X., Lu, L.Z. and Zhang, B.M., 1986. Paleomagnetic polarity of the Permian Emeishan Basalt in Sichuan. Geol. Review, 32: 465-469 (in Chinese with English abstract).

Zijderveld, J.D.A., 1967. AC demagnetization of rocks: analysis of results. In: S.K. Runcorn, K.M. Creer and D.W. Collinson, (Editors), Methods in Paleomagnetism. Elsevier, Amsterdam, pp. 254-286. 